\title{
Kolaborasi Produksi Konten YouTube melalui Multi-Channel Network: Studi pada Kreator Sandy SS dengan Collab Asia
}

\author{
Catleya Indah Lestari ${ }^{1 *}$, Irwansyah ${ }^{2}$ \\ ${ }^{1,2}$ Universitas Indonesia \\ *Email: catleya.indah91@ui.ac.id
}

Disetujui : 22 Februari 2021

Diterbitkan : 28 Februari 2021

\begin{abstract}
Abstrak
Perkembangan industri digital audiovisual, khususnya pada media sosial berbasis video YouTube, membuat para kreator konten video terus berkembang dan berubah. Penelitian ini akan menjelaskan bagaimana sebuah perusahaan multi-channel network (MCN) bekerja dan berkolaborasi dengan kreator demi mewujudkan produksi konten yang menarik dan layak tonton pada media sosial YouTube. Penelitian juga melihat bagaimana perusahaan multi-channel network dapat membantu kreator konten yang mengalami kesulitan dalam memproduksi konten dan menggunakan akun salurannya secara optimal. Peneliti menemukan bahwa kolaborasi produksi konten dengan menggunakan lima tahapan adopsi difusi inovasi oleh Everett Rogers melihat lebih dalam bagaimana Collab Asia sebagai sebuah perusahaan multi-channel network melakukan kolaborasi guna memproduksi konten video di YouTube, dapat berhasil dengan baik. Penelitian menunjukkan bahwa kelima tahapan difusi inovasi teradopsi dari kedua pihak baik Sandy SS sebagai kreator konten dan Collab Asia sebagai perusahaan multi-channel network yang menaunginya berjalan dengan baik.
\end{abstract}

Kata Kunci: difusi inovasi, YouTube, Multi-Channel Network, kreator konten

\begin{abstract}
Within the growth of the audio-visual digital industry, specifically on video-based social media, YouTube, requires video content creators to develop and transform themselves. This research will explain how a multi-channel network (MCN) company works and collaborates with creators to actualize an interesting content production and a worth-watching videos on YouTube. This research also will discern how a multi-channel network company helps their creators that in need to produce content and use their channel optimally. This research shows that content production collaboration using five stages of diffusion of innovations by Everett Rogers analyzes deeper on how Collab Asia as a multi-channel network company perform the collaboration to produce video content on YouTube works out well. This research shows that all five stages of diffusion of innovations from both sides, Sandy SS as content creator and Collab Asia as the multi-channel network company, goes well.
\end{abstract}

Keywords: diffusion of innovations, YouTube, Multi-Channel Network, content creator

\section{PENDAHULUAN}

Dewasa ini, manusia yang hidup pada era industri 4.0 mengalami perkembangan industri dalam berbagai sektor kehidupan dengan sangat pesat. Dengan kecerdasan dan kemampuan manusia era masyarakat 5.0 yang secara cekatan mengembangkan berbagai jenis pekerjaan dan keahlian yang dapat digunakan atau kreativitas yang diaplikasikan dalam kehidupan sehari-hari guna mencapai keuntungan ataupun merasakan kemudahan saat menjalankannya. Menurut Slameto (2019), masyarakat 5.0 bertujuan untuk membuat adanya tatanan masyarakat yang berpusat pada manusianya dengan adanya pengembangan sektor 
ekonomi dan dapat menikmati kualitas hidup manusia yang aktif, dimana kunci keberhasilannya merupakan gabungan adanya ruang digital dan nyata untuk menciptakan kehidupan yang berkualitas. Adanya ruang siber, berarti juga adanya koneksi internet yang membantu manusia dalam menghasilkan kreativitas dan karya, serta mendukung penuh pesatnya perkembangan kehidupan manusia saat ini. Apalagi dalam mengakses informasi yang dibutuhkan dalam mencapai kebutuhan, baik dalam skala prioritas sangat penting atau tidak, dan dengan berbagai jenis informasi yang dapat diakses dengan kegunaannya.

Agar manusia dapat memenuhi kebutuhannya, mereka dapat mengakses berbagai macam kanal yang biasanya disebut dengan media sosial. Media sosial merupakan salah satu sumber untuk mendapatkan informasi yang aksesnya juga sangat mudah digunakan oleh manusia pada umumnya. Menurut Kotler dan Keller (2009), media sosial merupakan media yang digunakan oleh konsumennya untuk berbagi tulisan, gambar, suara, dan juga video yang berisikan informasi baik dari seseorang ataupun sekelompok, dan juga sebaliknya. Dikutip dari Howard dan Parks (2012), media sosial merupakan media yang terdiri dari tiga bagian; (1) infrastruktur informasi dan alat yang dipakai untuk membuat dan membagikan isi media, (2) isi dari media tersebut yang dapat berupa macam-macam, seperti berita, pesanpesan pribadi, gagasan, dan produk budaya lainnya yang sudah dalam bentuk digital, dan (3) produksi serta konsumsi dari isi media itu sendiri yang berada dalam bentuk digital, adalah individu, kelompok atau organisasi, dan industri.

Media sosial sendiri merupakan wadah bagi para penggunanya untuk dapat dengan mudah berpartisipasi, berbagi, menciptakan konten, jejaring sosial, dan mendapatkan informasi secara virtual. Media sosial memiliki ragam jenis yang dapat digunakan oleh manusia dalam kehidupan sehari-hari. Terdapat enam jenis klasifikasi media sosial yang terdapat saat ini menurut Kaplan dan Haenlein (2010), yaitu proyek kolaborasi, blog, konten, situs jejaring sosial, virtual game world, dan virtual social world.

Penelitian ini akan lebih membahas YouTube, yang merupakan kanal media sosial dengan klasifikasi jenis konten, yang sudah digunakan oleh para penggunanya untuk membuat konten hasil para kreatornya ataupun untuk mengakses berbagai video yang berisi konten musik, hiburan, informasi, berita, pendidikan, politik, kebudayaan, showbiz, dan lainnya untuk para penontonnya. Dilansir dari laman YouTube (Youtube, 2020a; Youtube, 2020b), platform YouTube adalah salah satu media sosial berbasis video yang memiliki lebih dari 2 miliar pengguna atau berarti hampir dari sepertiga dari pengguna internet secara keseluruhan. Usia pengguna YouTube berada pada kisaran 18 hingga 34 tahun. YouTube telah menjangkau dan melokalisasi diri di lebih dari 100 negara dan 80 bahasa yang berbedabeda. Tiap harinya, tercetak satu miliar jam tayang dari seluruh pengguna YouTube di seluruh dunia menonton video-video pilihan mereka. YouTube merupakan situs web yang berguna dalam membagikan video. Penggunanya menggunakan platform ini untuk membuat, membagikan, dan menonton video yang dibuat oleh pengguna lain secara gratis (Chau, 2010).

Bahkan di Indonesia sendiri, dilansir dari KataData (2020), YouTube merupakan media sosial nomor satu di Indonesia. Survey We Are Social (Hootsuite, 2020) juga mengatakan bahwa 150 juta penduduk Indonesia aktif menggunakan media sosial dan dari berbagai media sosial tersebut, YouTube menjadi platform terbanyak yang diakses hingga 
sampai $88 \%$ dari total pengguna media sosial di Indonesia pada tahun 2019, disusul oleh WhatsApp dengan persentase sebanyak 83\%, Facebook sebesar 81\%, dan Instagram sebanyak $80 \%$.

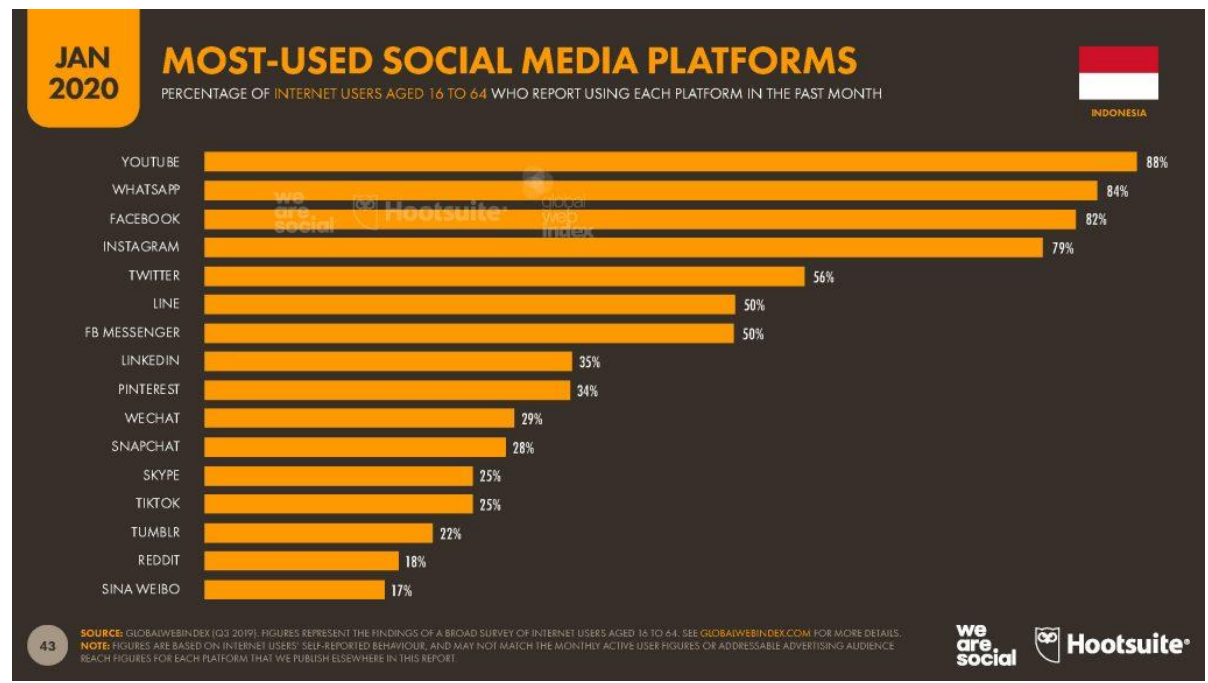

Gambar 1. Data Pengguna Media Sosial di Indonesia

(Hootsuite, 2020)

Di Indonesia, rata-rata waktu penggunaan internet melalui berbagai perangkat (ponsel, laptop, komputer, dan lainnya) tiap harinya berada di angka 8 jam, 36 menit dengan jumlah rata-rata penggunaan media sosial dengan berbagai perangkat (ponsel, laptop, komputer, dan lainnya) sebesar 3 jam, 26 menit. Menurut Google Indonesia, pertumbuhan video YouTube di Indonesia pun juga sangat cepat dan YouTube Indonesia telah menjadi yang paling besar se-Asia Pasifik (Yuniar, 2015). Sepuluh konten yang paling banyak ditonton di Indonesia pada platform YouTube adalah, musik, tutorial, komedi, cuplikan film, film non-Indonesia, user-generated content, pendidikan, hiburan, sepak bola, dan juga gaya hidup. YouTube sendiri sudah lebih menjadi platform online untuk membagikan dan menyebarkan konten. Fitur teknis dan sosialnya yang unik yang telah membantu formasi dari keterlibatan dari anggota komunitasnya, sehingga menarik minat penggunanya untuk berkolaborasi dan memproduksi produk media yang kreatif, ekspresif, dan juga orisinil buatan sendiri (Jenkins, 2009).

Dengan semakin berkembangnya industri media sosial konten khususnya pada platform YouTube, maka akan sangat masuk akal bila semakin banyak pengguna, baik yang hanya mengonsumsi konten maupun yang akan memproduksi konten. Kreator yang akan berfokus untuk mengolah, memproduksi, mengunggah, dan menyebarkan kontennya pasti memiliki banyak detil dan juga tahapan yang harus dilakukan guna sebuah konten akhirnya dapat dinikmati oleh audiens mereka masing-masing.

Seorang kreator seyogyanya dapat membuat sebuah konten dan memang didasari atas keinginan, minat, perhatian atau urusan, atau sekadar hanya mengisi waktu luang. Sebuah konten juga dibuat dapat berdasarkan dari sebuah hal unik, hal biasa, hal menarik, hal penting, hal yang informatif, dan segala bentuk konten yang dapat dikemas dengan adanya 
proses kreatif, hingga akhirnya menjadi sebuah konten yang dapat dinikmati. Menurut Kevin Hendrawan dikutip Tirto.id (Putri, 2018), seorang YouTuber asal Indonesia yang memiliki subscriber sebanyak hampir 2 juta orang dan telah mengunggah sebanyak 520 video tercatat tanggal 27 Maret 2020, mengatakan bahwa proses untuk membuat konten sendiri sudah cukup memakan waktu dan tenaga. YouTuber atau kreator lain sudah memiliki modal kamera bagus dan perlengkapan bagus. Kevin menyatakan:

Tapi, sekali lagi, dari penghasilan YouTube sendiri itu sudah dipotong pajak. Karena biasanya begini, di YouTube itu ada perantaranya. Namanya MCN atau Multi-Channel Network. Kalau YouTuber bergabung dengan ini, dan saya bergabung dengan ini, itu nantinya penghasilan yang kami dapatkan sudah langsung dipotong pajak. Jadi saat kami terima pendapatan dari YouTube itu sudah ada rinciannya berikut pajaknya. Per hari pun kelihatan penghasilannya. (Putri, 2018).

Berdasarkan penjelasan tersebut dapat disimpulkan bahwa mengelola dan mengatur konten pada media sosial terutama YouTube tidak mudah. Banyak detail dan proses yang harus dijalankan dan terkadang penggunanya dapat menemukan banyak isu yang tidak dengan mudah dapat dengan mudah diselesaikan dari waktu ke waktu. Maka dari itu, terdapat pihak ketiga atau perantara yang dapat membantu kreator dalam mengelola sistem dan alur monetisasi yang biasanya cukup memusingkan kreator-walau bukan mustahil bagi seorang kreator untuk mengelola saluran YouTube mereka secara mandiri. Selain mengurus dan mengelola monetisasi, perusahaan ini dapat membantu para kreator untuk tidak menemui perselisihan dengan peraturan yang diterapkan oleh YouTube. Perusahaan ini juga membantu adanya pelaksanaan kolaborasi produksi konten antara perusahaan dan kreator. Sebuah perusahaan ini dikenal dengan nama Multi-Channel Network (MCN). Dikutip dari situs resmi YouTube, MCN adalah sebuah perusahaan yang bekerja dengan platform media sosial konten video seperti YouTube dan menawarkan jasa, dan kepengurusan dalam areaarea yang sudah disediakan seperti produk, programming, promosi silang, manajemen rekanan, manajemen hak digital, monetisasi, dan pengembangan channel.

MCN adalah sebuah perusahaan penyedia produk dan jasa layanan pihak ketiga yang membantu menawarkan para kreator konten dan untuk dapat membantu sebuah channel atau kreator dalam urusan back-end di YouTube, seperti pengembangan channel serta audiens, pengembangan dan pembuatan konten, kolaborasi antar sesama kreator YouTube - apalagi yang berada dalam satu wadah perusahaan MCN tersebut, manajemen hak digital, serta monetisasi dan/ ataupun penjualan. Kreator konten tersebut akan melakukan pembahasan, diskusi, dan berakhir dengan kontrak kerja sama dengan pembagian hasil dan lama kontrak sesuai dengan perjanjian yang telah disepakati oleh kedua pihak baik dari sisi perusahaan MCN dan sisi kreator tersebut (Guntara, 2018).

Dengan adanya bantuan dan kemudahan yang ditawarkan oleh MCN untuk kreator, tak heran banyak yang ingin bergabung menjadi kreator yang berada di bawah naungan MCN. Seluruh hal yang ditawarkan oleh perusahaan MCN dengan kreator tersebut akan disebut dengan kolaborasi produksi konten. Dari beberapa daftar MCN yang terdapat di Indonesia, salah satu MCN yang paling menjanjikan dan cukup disegani adalah Collab, Inc. atau biasa 
dikenal dengan Collab Asia. Dikutip dari profil perusahaan Collab Asia (Collab, 2020; Collab Asia, 2020):

Collab Asia merupakan sebuah studi konten digital dan juga jaringan influencer media sosial. Collab Asia bekerja sama dengan talenta baru dan yang sudah bergabung dari seluruh penjuru Asia untuk membuat konten yang relevan serta menarik bagi audiens. Collab Asia adalah perusahaan Multi-Channel Network (MCN) yang mendukung kreator global dan influencer media sosial untuk berkarya secara kreatif dan membantu pare kreator untuk mendapatkan penghasilan dari hasil karya mereka.

Collab Asia sendiri merupakan entitas yang asalnya merupakan dari Amerika, dengan nama perusahaan "Collab". Collab sendiri secara resmi dibuka untuk menjalankan bisnisnya pada tahun 2012, namun semuanya dimulai pada tahun 2006 di mana penemu Collab (James McFadden, Tyler McFadden, dan Will McFanders) memiliki studio sendiri di kota Los Angeles, Amerika Serikat. Pada 2007 YouTube memulai sebuah program yang dinamakan YouTube's Partner Program (YPP) yang berusaha memberdayakan kreator independen yang berupaya untuk bertransformasi dari kreativitas buatan sendiri, menjadi sebuah karir hiburan yang berkembang secara sepenuhnya. Mereka lalu berkolaborasi dengan salah satu veteran YouTube, Soung Kang. Hingga sekarang Collab masih menjadi salah satu yang terbaik. Kreator andalan Collab beberapa di antaranya adalah David Dobrik (17,6 juta subscriber dengan total unggahan video sebanyak 625 video), Eh Bee Family (8,93 juta subscriber dengan total unggahan video sebanyak 800 video), dan Gabbie Hanna/The Gabbie Show (6,14 juta subscriber dengan total unggahan video sebanyak 368 video). Data ini dikumpulkan per tanggal 3 Juni 2020, sehingga kemungkinan akan terjadi kenaikan atau penurunan angka, walau tren yang terjadi akan terus meningkat. Entitasnya, yaitu Collab Asia, sudah tidak lagi bergantung secara finansial dan hukum dari Collab yang berada di Amerika sejak 2017.

Mosqueda (2019) menyebutkan, Collab Asia sendiri telah meraih 7,5 juta dolar dan mencapai pendanaan Series B oleh investor. Collab Asia sebagai global brand sendiri sudah berdiri di beberapa negara, yaitu Korea Selatan, Hong Kong, Filipina, Singapura, Jepang, Malaysia, dan juga Indonesia. Saat ini Collab Asia sudah memiliki lebih dari 1.500 kreator, dengan kreator paling banyak adalah dari Indonesia, sebanyak kurang lebih 600 kreator, berdasarkan data dari Collab Asia Indonesia. Secara keseluruhan, telah mendapatkan 125 juta subscriber dari seluruh entitas Collab Asia dan dua milyar views bulanan di YouTube.

Collab Asia Indonesia sudah berdiri sejak Oktober 2017 dengan jumlah kreator mencapai 600 kreator, per data bulan Juni 2020. Beberapa kreator konten asal Indonesia yang berada di bawah naungan Collab Asia dan memiliki subscriber dan viewers yang terbilang cukup tinggi, antara lain: Bang Alex (memiliki 3,24 juta subscriber dengan total unggahan video sebanyak 740 video), Jerome Polin "Nihongo Mantappu" (memiliki 3,58 juta subscriber dengan total unggahan video sebanyak 312 video), Step by Step ID (memiliki 1,77 juta subscriber dengan total unggahan video sebanyak 248 video, Nofin Asia (3,88 juta subscriber dengan total unggahan 156 video), dan juga Sandy SS (684 ribu subscriber dengan total unggahan video sebanyak 30 video) masih banyak lagi lainnya. Data ini dikumpulkan per tanggal 3 Juni 2020, sehingga terjadi kemungkinan akan terjadi 
kenaikan atau penurunan angka, walau tren yang terjadi akan terus meningkat. Para kreator yang berada di bawah naungan Collab Asia juga terdiri dari beberapa genre atau jenis video, seperti musik, gaming, lifestyle, kecantikan atau beauty, humor atau comedy, dan lainnya.

Collab Asia juga menangani semua aspek yang dikerjakan oleh MCN pada umumnya, yaitu mengelola hak digital, analisis data, dukungan desain dan proses kreatif, jaringan secara global, opsi iklan premium, serta dukungan pendapatan iklan atau yang sedang peneliti fokuskan, yaitu kolaborasi produksi konten, dengan adanya pengembangan saluran media sosial YouTube yang dimiliki oleh kreator dan juga jasa lain yang ditawarkan oleh Multi-Channel Network itu sendiri.

Mengapa para MCN ini melakukan proses kolaborasi produksi konten dengan para kreatornya? Dikutip dari Merdeka (Azzura, 2015), MCN sangat membantu kreator untuk mengembangkan karya-karya mereka dan bahkan bisa membantu kebutuhan kreator diluar YouTube pula. Pada penelitian ini, peneliti akan berfokus pada proses kolaborasi produksi konten yang dilakukan oleh MCN Collab Asia dan kreatornya. Sebuah kolaborasi produksi konten seperti ini merupakan sebuah inovasi, di mana kreator sebagai produsen utama sebuah konten tidak lagi secara mandiri membuat video untuk diunggah ke YouTube. Collab Asia sebagai perusahaan MCN akan membantu problem kreator dalam berkarya dengan adanya aturan dan petunjuk resmi yang diberikan oleh YouTube. Seorang kreator sebenarnya bisa berdiri sendiri tanpa adanya bantuan MCN untuk menghasilkan konten ke YouTube. Namun ketika menemukan problem yang cukup rumit dan terperinci, akan menjebak dan menyulitkan kreator dan dapat mengurungkan niatnya untuk berkarya lebih lanjut.

Dilansir dari CNN Indonesia (2018), Raditya Dika, seorang kreator terpandang dan relatif lama berkarya di platform YouTube mengakui, ia mengalami kesulitan dalam mempertahankan konsistensi dalam memproduksi konten yang berkualitas pada berbagai platform digital. Ia juga mengatakan bahwa banyak rekan-rekannya yang ingin membuat konten di media sosial seperti YouTube, tapi tidak tahu caranya.

Untuk menjadi seorang kreator konten di YouTube, diperlukan pengeluaran dana yang tidak sedikit demi menunjang dan membuat konten yang menarik dan layak ditonton. Pendapatan dari YouTube pun tidak menetap, bahkan ada yang harus bergantung pada sponsor untuk bisa bertahan. Perusahaan MCN dengan mudah akan dapat membantu isu yang terjadi ketika seorang kreator menemui beberapa problem berkaitan dengan pengunggahan, monetisasi, rincian data back-end yang kadang membingungkan, pemasaran konten, dan berbagai hal lainnya. Maka, adanya kolaborasi produksi konten antara kreator dan MCN di YouTube merupakan sebuah inovasi yang dapat membantu kreator dalam menyelesaikan masalah. Ketika kreator menyetujui berkolaborasi dalam memproduksi sebuah konten, maka kreator harus dengan seksama meneliti seluruh rincian dan detail yang diberikan pihak MCNagar berjalan sesuai kesepakatan (Kurnia, 2018).

Penelitian ini menggunakan teori difusi inovasi. Difusi inovasi adalah sebuah teori yang dikemukakan Everett Rogers pada tahun 1964 yang memberikan gambaran mengenai bagaimana sebuah ide dan teknologi baru tersebar. Difusi inovasi adalah tahap di mana seseorang akan menilai adanya ide baru, lalu dihubungkan dengan situasi kehidupan pada masyarakat saat ini atau di masa akan datang, lalu masyarakat nantinya akan mencoba hal tersebut atau tidak. Selanjutnya, akan diterapkan untuk ditelaah kegunaannya, apakah cocok 
dengan situasi yang dialaminya, lalu akan ada fase mengadopsi ide baru tersebut lalu dan digunakan secara luas (Rogers, 2010).

Terdapat empat elemen utama dalam teori difusi inovasi, yaitu (1) inovasi (the innovation), sebuah ide, praktik, atau objek yang dianggap baru oleh seseorang dalam melakukan adopsi, (2) saluran komunikasi (communication channels) adalah medium dimana seseorang mendapatkan pesan atau informasinya dari seseorang dan disampaikan ke orang lain, (3) waktu (time), dimana terdapat periode waktu yang dibutuhkan seseorang untuk berproses dalam menentukan adopsi sebuah inovasi, dan yang terakhir (4) sistem sosial (social systems) yaitu adanya anggota-anggota yang saling berhubungan dan tergabung untuk meraih tujuan bersama (Rogers, 2010). Teori ini cukup banyak digunakan dalam berbagai hal, terutama penggunaan penyebaran informasi dan adanya sosialisasi ide atau konsep baru. Difusi inovasi sendiri berarti penyebaran sesuatu berupa teknologi, kebudayaan, ataupun ide-ide yang disampaikan dari satu pihak yang nantinya akan diterima oleh pihak lainnya (Haryadi, 2018).

Penelitian sebelumnya menjelaskan, proses adopsi budaya kerja menggunakan teori difusi inovasi dalam mengevaluasi saluran komunikas memengaruhi tercapainya tujuan organisasi (Rusmiarti, 2016). Difusi inovasi memengaruhi adanya penerimaan dari teknologi yang digunakan pengusaha (Fatonah dan Afifi, 2014). Pada kasus pemasaran politik, komunikator memainkan peran yang penting dalam proses difusi inovasi, guna melihat kesuksesan dari inovasi yang teraplikasikan di lapangan maka harus terdapat kemampuan untuk menerima adanya difusi inovasi kepada audiensnya (Putri, 2013). Menurut Rogers dalam Setijaningrum (2016), terdapat lima tahapan yang akan terjadi ketika seseorang telah mengadopsi sebuah inovasi, yaitu knowledge, persuasion, decision, implementation, dan confirmation.

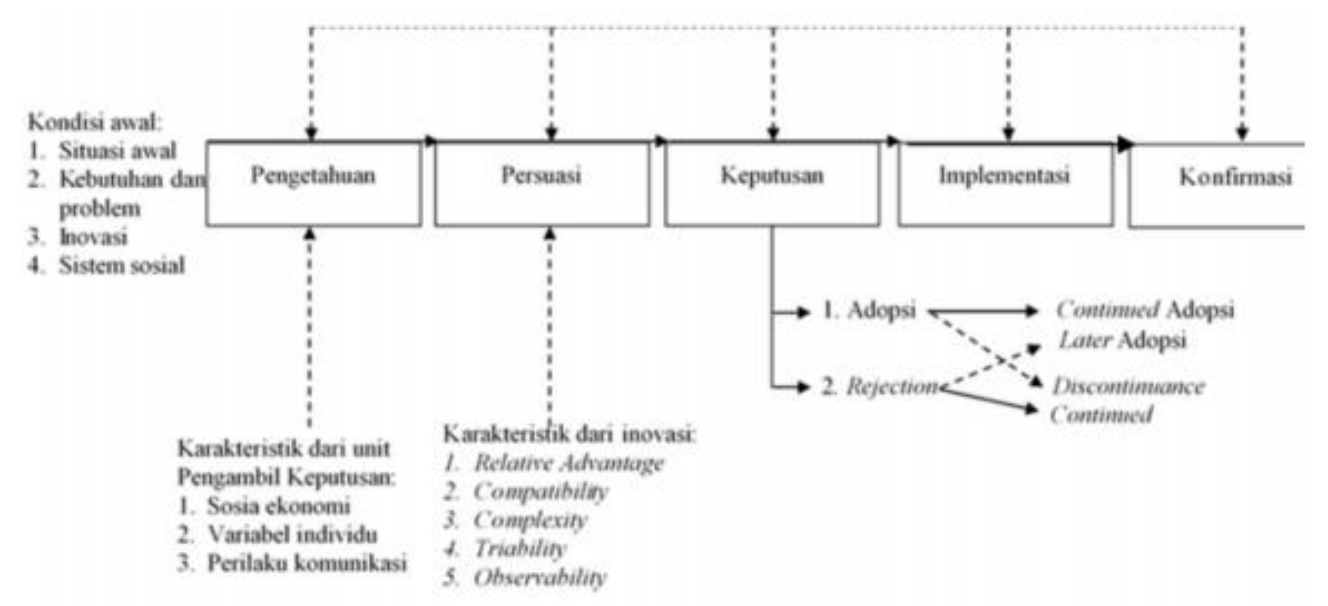

Gambar 2. Tahapan adopsi inovasi oleh Everett M Rogers

Penelitian ini akan menjelaskan peran MCN yang berfungsi sebagai pihak ketiga dalam kolaborasi produksi konten dengan kreator di media sosial YouTube dan pelaksanaan lima tahapan yang telah dilakukan berdasarkan teori adopsi inovasi oleh Everett M Rogers. 


\section{METODOLOGI PENELITIAN}

Penelitian ini menggunakan pendekatan kualitatif deskriptif. Konsep pendekatan kualitatif yaitu berusaha menggabungkan dan menganalisis data untuk selanjutnya dikembangkan menjadi konsep yang baru, merumuskan definisi untuk konstruksi utama, dan menghubungkan keseluruhannya. Pada setiap penelitian kualitatif,yang dibutuhkan adalah deskripsi tersirat yang dituangkan dalam bentuk deskripsi atau narasi dari sebuah tindakan spesifik yang menghubungkan antara ide dengan data (Neuman, 2014). Deskriptif digunakan untuk menjelaskan kondisi keadaan, ataupun sifat-sifat dari terjadinya sebuah fenomena (Wilmer \& Dominick, 2013).

Penelitian ini juga menggunakan metode studi kasus yaitu kumpulan aktivitas penelitian yang dilakukan secara detil dan komprehensif mengenai seseorang, sebuah peristiwa, atau aktivitas guna mendapatkan jawaban yang mendalam mengenai penelitian tersebut (Rahardjo, 2017). Studi kasus yang digunakan pada penelitian ini adalah studi kasus tunggal holistik, yang berfokus pada sebuah peristiwa dalam penelitiannya (Yin, 1994). Untuk lebih mendalami dan menemukan jawaban dari sumber yang kredibel, teknik pengumpulan data dengan wawancara dan observasi. Wawancara virtual dilakukan pada awal Juni 2020 dengan pihak MCN Collab Asia yaitu Mega Indriani (Ega) selaku Production Senior Manager, serta salah satu kreator eksklusif naungan Collab Asia, yaitu Sandy Saputra (Sandy SS), seorang aktor media sosial yang memiliki 684 ribu subscriber di YouTube dengan total unggahan video sebanyak 30 video. Observasi dilakukan dengan pengumpulan data kepustakaan dari jurnal atau studi terdahulu, data-data dari situs kredibel berkaitan dengan penelitian, serta mengambil data-data yang terdapat di platform YouTube.

\section{HASIL DAN PEMBAHASAN}

Pada teori difusi inovasi, terdapat lima tingkat oleh pengadopsi dalam teori difusi inovasi yaitu awareness, interest, evaluation, trial, dan adoption (Lumen Learning, 2017). Penelitian ini mengolah data dari hasil wawancara dengan melihat jawaban mereka berdasarkan dengan tahapan-tahapan yang telah diperoleh setelah adanya proses adopsi. Kedua informan diberi pertanyaan mengenai kelima tahapan, namun dalam sudut pandang yang berbeda dalam rangka mencapai pertemuan kolaborasi produksi konten YouTube. Ega diberi pertanyaan tentang proses tahapan adopsi inovasi dari pihak Collab Asia, sedangkan Sandy diberi pertanyaan mengenai proses tahapan inovasi dari sisi kreator.

\section{Tahap Pengetahuan (Knowledge)}

Pada tahap pengetahuan (Knowledge), seseorang belum mengetahui adanya inovasi terbaru. Maka dari itu, informasi dan pengetahuan mengenai inovasi diharapkan dapat disebarluaskan melalui saluran komunikasi yang ada, baik dari media massa ataupun komunikasi interpersonal yang terjadi di masyarakat (Setijaningrum, 2016).

Pada tahapan ini menurut Ega, Collab Asia lebih banyak melakukan pendekatan secara langsung atau komunikasi interpersonal kepada calon kreator yang hendak diajak bergabung dengan Collab Asia. Menurut Ega, karena pada awalnya Collab Asia masih berusia cukup muda dan baru "lahir" di Indonesia pada Oktober 2017, maka strategi yang digunakan harus lebih spesifik dan mengarah kepada kreator yang memang sudah lolos pada tahap scanning, 
atau memindai seorang kreator yang sudah dituju dengan segala ketentuan yang berlaku. Ini dilakukan oleh tim Collab Asia setelah adanya proses talent scouting atau pencarian talenta kreator.

Makanya bener-bener pas awal kita gunain direct approach dan rekomendasi 'natural' dari masing-masing kreator ini ke kreator lainnya, sampe akhirnya mereka tahu tentang Collab Asia Indonesia (Ega, 2020).

Proses pemberian pengetahuan dan informasi melalui komunikasi interpersonal sangat dibutuhkan di awal adanya inovasi. Saluran komunikasi yang digunakan menggunakan surat elektronik atau e-mail ataupun pesan langsung (direct message) melalui media sosial ke masing-masing kreator yang sudah dituju. Strategi Collab Asia cukup efektif mengingat di awal pembentukan inovasi yang cukup baru ini, sesuatu yang cukup detail dan kompleks perlu disampaikan melalui penjelasan secara terperinci dan bersifat personal.

Sandy juga mengatakan, ketika pihak Collab Asia memberi informasi mengenai inovasi yang ditawarkan, pendekatannya secara personal melalui pesan langsung atau direct message di media sosial Instagram. Sandy sbelumnya sudah berkarya di beberapa media sosial seperti Instagram, TikTok, dan YouTube. Salah seorang tim Collab Asia menghubungi Sandy karena karya Sandy dinilai cocok dengan konten yang dikumpulkan tim Collab Asia. Konten Sandy awalnya hanya akan diklaim dan dimonetisasi per video yang Sandy buat, namun mereka melihat terdapat potensi dari pengembangan konten Sandy.

Collab Asia DM (direct message) di akhir tahun 2019 dan DM duluan, dihubungi untuk klaim video Sandy dan masuk ke konten YouTube-nya LucuLucuVideo dari Collab Asia (Sandy, 2020).

Pada tahap ini, tim Collab Asia telah menyampaikan penawaran inovasi yang mereka miliki dan Sandy juga mendapatkannya melalui saluran media sosial dengan pendekatan komunikasi interpersonal yang terjadi pada akhir 2019. Sandy ditemukan karena video yang dibuat oleh Sandy muncul pada kumpulan video yang sesuai dengan konten yang dicari oleh Collab Asia, sehingga kolaborasi produksi konten diperkirakan dapat bertemu antara kedua belah pihak.

\section{Tahap Persuasi (Persuasion)}

Pada tahap yaitu tahapan di mana seseorang sudah mulai tertarik pada inovasi dan dengan aktif mencari informasi ataupun keterangan lebih lanjut mengenai inovasi tersebut. Inovasi ini bersangkutan dengan adanya karakter inovasi seperti adanya kelebihan inovasi, tingkat keserasian, kompleksitas, dapat dicoba atau gunakan, ataupun dapat dilihat atau secara nyata wujudnya terlihat (Setijaningrum, 2016).

Pada tahapan ini, Ega mengatakan bahwa Collab Asia melakukan berbagai cara untuk meyakinkan seorang kreator yang sudah diberi informasi/ pengetahuan tentang inovasi yang dimiliki mereka, agar kreator tersebut yakin dengan produk dan jasa yang ditawarkan oleh Collab Asia. Contohnya dengan mengajak kreator untuk datang ke kantor Collab Asia yang berada di kawasan elite Sudirman, Jakarta, untuk meyakinkan kreator bahwa inovasi yang ditawarkan berasal dari perusahaan yang memiliki modal dan sarana memadai. Ega juga 
mengatakan, pada pemberitahuan awal tanpa ada iming-iming bersifat overselling untuk menghindari tindakan atau perkataan tidak diharapkan.

Kita akan tetap realistis dan tidak nawarin dengan hal yang gak pasti, misal kalo kalian gabung di Collab Asia nanti kalian bisa dapat brand deals sejumlah segini, atau gimana biar mereka join, itu gak pernah (Ega, 2020).

Proses persuasi dijalankan dengan tujuan mengajak kreator agar dapat berkolaborasi untuk memproduksi konten, namun konteks produk dan jasa yang mereka sediakan sesuai dengan yang dikomunikasikan. Bila pada tahap pengetahuan lebih bersifat kognitif, namun menurut Rogers (2010), pada tahap persuasi lebih bersifat afektif yang menyangkut perasaan personal dari individu ini sendiri. Sehingga akan ada keterlibatan yang lebih mendalam dari seseorang.

Ega mengatakan, terdapat beberapa hal yang mendiferensiasikan Collab Asia dengan MCN lainnya, yaitu Collab Asia tersebar di beberapa negara Asia dengan kreator yang juga berasal dari negara-negara tersebut. Ega menjelaskan, terdapat kesempatan untuk para kreator dari satu negara yang nantinya bisa berkolaborasi dengan kreator dari negara lainnya. Ini menjadi daya jual tersendiri yang tidak dimiliki oleh MCN lain, bahwa terdapat sebuah komunitas besar dan tersebar yang dibuat oleh Collab Asia sehingga dapat memberikan keuntungan lebih bagi kreatornya.

Biasanya kita juga akan menginformasikan mengenai network Collab Asia sendiri yang ada di region lain seperti Jepang, Korea, Singapura, Filipina, Malaysia, dan lain-lain. Nah kita lihat juga, kalo misalnya ternyata kreator ini punya konten atau potensi yang dapat kita gabungkan dengan kreator yang ada di region lain itu. Contoh, kayak satu kreator suka joget K-Pop, nah kita bisa sambungkan dia kepada kreator atau artis kita yang ada di Korea dan bisa melakukan kolaborasi bareng kayak ketika si kreator Korea ini bisa (membuat video) react ke K-Pop video dance mereka, atau si artis Korea ini rilis lagu baru terus nanti para kreator Indonesia atau region lain bisa pakai lagu mereka menjadi backsound untuk video K-Pop dance mereka. Jadi nanti simbiosis mutualisme jatuhnya, ya (Ega, 2020).

Dari pihak kreator, menurut Sandy, saat terjadi tahapan persuasi dari tim Collab Asia. Sandy merasakan bahwa ia diperlakukan secara profesional namun dengan pembawaan yang informal. Ini sesuai dengan karakter Sandy yang menyenangkan, sehingga ia tidak merasa ragu.

Tim Collab Asia juga baik dan ramah semua, pas (Sandy) diajak ke kantor. (Sandy) diajak main, diajak (hadir dan berpartisipasi di) event, jadi gak ragu sama sekali. Ada tim juga yang handle (secara) profesional ngurusin Sandy dan pengembangan konten serta channel Sandy (Sandy, 2020).

Pada tahap ini, proses persuasi juga dirasakan Sandy dari pihak kreator untuk merasakan keuntungan dan penawaran inovasi yang dihadirkan dengan waktu tidak sebentar. Terdapat beberapa aktivitas dan proses seiring berjalannya waktu. Sandy menganggap bahwa ia telah merasakan pengalaman dari proses persuasi yang lebih dari ekspektasi, dengan adanya perlakuan yang tidak hanya diberikan oleh salah satu perwakilan, namun banyak karyawan dari tim Collab Asia, sehingga sistem sosial itu mendukungnya bergabung untuk berkolaborasi memproduksi konten YouTube bersama Collab Asia. 


\section{Tahap Keputusan (Decision)}

Pada tahap keputusan, seseorang akan mengambil konsep dari inovasi tersebut dan dia akan mempertimbangkan kelebihan atau kekurangan dari inovasi itu sendiri, lalu nanti dia akan memutuskan untuk mengadopsi atau malah menolak inovasi yang ditawarkan sebelumnya (Setijaningrum, 2016). Keputusan dapat memberikan dua hasil yang berbeda, menerima atau menolak. Pada tahap ini seseorang dapat menerima secara penuh dari inovasi yang ditawarkan, sedangkan penolakan pun sangat mungkin untuk terjadi dalam proses keputusan inovasi tersebut. Rogers (2010) mengatakan ada dua jenis yang berbeda dari penolakan, yaitu (1) active rejection di mana seseorang telah mencoba inovasi dan memikirkan untuk menerimanya, namun dalam prosesnya akhirnya terjadi penolakan, dan (2) passive rejection di mana seseorang benar-benar tidak berpikir untuk mengadopsi inovasi tersebut sama sekali.

Pada penelitian ini, tahapan keputusan lebih berfokus kepada bagaimana sang penerima inovasi atau kreator menetapkan pilihan pada keputusannya untuk menerima atau menolak inovasi. Inovasinya yaitu tawaran produk dan jasa Collab Asia dalam melakukan kolaborasi produksi konten pada YouTube.

Ega mengatakan, Collab Asia akan terus mendampingi dan memantau kreator saat menunggu kreator memberikan jawaban atau keputusan. Agar kedua pihak merasa nyaman dan terhindar dari ketidakpastian, maka tim Collab Asia menawarkan pengaturan jadwal untuk menyelaraskan timeline kedua belah pihak. Nantinya, kreator juga bisa menentukan keputusan yang akan disampaikan sesuai waktu yang telah disepakati bersama.

Kita akan atur timeline sama calon kreator ini, kira-kira (bisa) kita follow up kapan (mengenai keputusannya). Biasanya mereka akan melakukan riset mengenai $\mathrm{MCN}$, atau nanya sama temen-temennya yang udah pernah gabung dengan Collab, atau MCN lain, nah itu biasanya kita akan atur waktu janjian untuk kita follow up dan nanti kreatornya bisa kasih jawaban dia (pada waktu yang ditentukan). Nah, biasanya kalo dia mengiyakan, maka bisa kita proses ke tahap selanjutnya untuk proses signing. Kalo pun enggak, kita akan terus keep contact dengan calon kreator ini (Ega, 2020).

Menurut Ega, penolakan dalam proses penawaran inovasi yang dilakukan Collab Asia pada kreator kerap terjadi. Namun, bukan berarti tim Collab Asia menutup pintu kerja sama, mereka justru terus mencoba berkomunikasi dengan kreator yang menolak tawaran inovasi mereka. Pada tahapan keputusan berlangsung, tim Collab Asia terus mengawal kreator dalam penyampaian keputusan yang akhirnya dapat menghasilkan respons positif atau negatif. Jika kreator telah melakukan dua tahapan proses pengetahuan dan persuasi dengan baik, maka ketika memberikan keputusan yang positif kepada Collab Asia, akan langsung dibuatkan kontrak kerja sama dan selanjutnya dapat melakukan kolaborasi untuk memproduksi konten bersama. Waktu tahapan ini tidak menentu, dapat berlangsung sebentar atau lama. Penandatanganan kerja sama bisa dilakukan secara langsung maupun secara digital seperti melalui pesan elektronik atau $e$-mail.

Menurut Sandy, proses pengambilan keputusan pada dirinya tidak berlangsung terlalu lama setelah dua tahapan pengetahuan dan persuasi. Meski dia yang mengadopsi inovasi 
yang ditawarkan, namun Sandy tetap membutuhkan opini atau masukan dari orang lain untuk mengadopsi inovasi tersebut. Menurut Tolba \& Mourad (2011), ada dua faktor penting yang membuat seseorang dapat terpengaruh difusi inovasi, pertama adalah faktor individu dan yang kedua adalah faktor budaya. Temuan penelitian ini, Sandy membutuhkan opini dari orang-orang terdekatnya agar semakin yakin dalam mengambil keputusan untuk berkolaborasi bersama Collab Asia.

Sandy sempet nanya-nanya ke teman-teman dan mama juga, mereka support. (Mama Sandy mengatakan) kalo menurut Sandy nyaman dan paham, sesuai di industri (yang dijalankan oleh) Sandy, jadi mama setuju aja. Temen-temen juga support, mereka setuju asalkan Sandy senang dan aman (Sandy, 2020).

Opini-opini tambahan tersebut yang membuat Sandy semakin yakin untuk bekerja sama dan akhirnya menandatangani kontrak kolaborasi guna memproduksi konten YouTube. Untuk kasus Sandy, kerja sama terjadi secara eksklusif, sehingga media sosial lainnya juga dikelola bersama Collab Asia.

\section{Tahap Implementasi (Implementation)}

Pada tahap implementasi, seseorang akhirnya merasakan langsung inovasi yang telah ia putuskan, tergantung dengan situasi yang terjadi. Pada tahap ini, seseorang akhirnya akan menentukan keuntungan dari inovasi tersebut dan mencari lebih lanjut mengenai hal yang sudah disampaikan di awal (Setijaningrum, 2016).

Pada tahap ini, proses penandatanganan kontrak kerja sama dilakukan setelah melalui diskusi dan kesepakatan antara Collab Asia dengan kreator. Collab Asia sendiri sebagai MCN membantu pengembangan channel serta audiens, pengembangan dan pembuatan konten, kolaborasi kreator, manajemen hak digital, serta monetisasi dan/ ataupun penjualan. Di luar kerja sama untuk memproduksi konten YouTube, Collab Asia juga dapat membantu kreator untuk mengelola akun media sosial lain seperti TikTok, Instagram, dan lainnya sesuai bentuk kerja sama yang disepakati kedua belah pihak. Di Collab Asia, ini disebut sebagai kerja sama eksklusif, sedangkan kerja sama non-eksklusif hanya berfokus pada produksi konten di YouTube.

Pada tahap implementasi, Collab Asia pun siap menyediakan produk serta jasa yang sudah disepakati kedua belah pihak dan melaksanakan kewajiban sesuai prosedur yang ada. Setiap kreator pun akan mendapatkan kesempatan dan perlakuan yang sama sesuai dengan kesepakatan yang sudah ditentukan kedua belah pihak. Collab Asia langsung melakukan implementasi inovasi, dimulai dengan analisis channel di awal hingga kebutuhan kecil yang cukup esensial. Collab Asia pun akan menawarkan beberapa kebutuhan yang mungkin dibutuhkan kreator, namun keputusan terhadap tawaran itu tergantung kreator.

Kita juga bisa provide mereka dengan kebutuhan channel art seperti desain grafis, poster thumbnail, dan segala macemnya. Ada aja channel di awal yang mereka gak terlalu merhatiin branding dan posternya (memiliki desain) super simpel gitu misal pake teks doang ga ada desain, nanti kita akan bantu tawarkan mereka dengan bilang kalo menurut kita bisa nih ditambah A, B, C, agar lebih appealing. Lalu kalo mereka setuju, kita akan bikin semuanya. Kalo untuk ide konten dan segala macemnya, biasanya kita akan lebih ke suggest, gak bersifat mandatory 
kalo mereka harus ngikutin saran kita, sebenernya enggak. Karena dari sisi Collab Asia sendiri kita menghargai sisi kreator, jadi konten kreator itu gak gampang. Lo harus liat mood lo, ngeliat timing masing-masing seperti apa, nah ketika udah kita kasih suggestion dan kita present, semuanya akan kembali ke kreator (Ega, 2020).

Menurut Sandy, Collab Asia memudahkannya dengan adanya jasa dan produk yang biasanya tidak dapat ia akses dengan mudah bahkan beberapa di antaranya membutuhkan biaya yang cukup tinggi, demi terciptanya konten menarik dan layak ditonton audiensnya. Bahkan ia bergurau, bahwa dirinya hanya butuh membawa badan dan siap beraksi di depan kamera.

Collab Asia bener-bener serius mengurusin Sandy. Persiapan konten bentuknya akan dua arah, nanti Sandy juga akan ngasih tau apa yang ide apa yang Sandy kasih ke Collab. Sering juga kan, beberapa kalo syuting di studio Collab Asia di Senayan. Nah itu set up video akan udah disediakan dari Collab, kamera, lighting, mikrofon, semua alat pendukung sudah disiapkan jadi Sandy tinggal menjadi Sandy, dan action (Sandy, 2020).

Collab Asia juga menawarkan kerja sama eksklusif, yang memiliki lebih banyak keuntungan dari kerja sama non-eksklusif_yang juga sudah memiliki paket lengkap. Sandy sendiri merupakan kreator eksklusif di Collab Asia, sehingga mendapat produk dan jasa yang lebih detail dan beragam dan mendapat lebih banyak keuntungan. Menurut Ega, kreator akan sangat terbantu bila bergabung ke manajemen MCN.

Bener-bener kita bantu dari A sampai Z, mulai dari proses brainstorm ide, konten, deals dia, syuting, editing, perkembangan channel dia dari YouTube sampai adanya adaptasi ke platform lain, itu semuanya dari kita. Kasarnya, kreator udah tinggal duduk manis aja gitu, he he. Mereka juga gak perlu mikirin judul, caption, meta-tagging, description, desain, backlink, bikin promo, kan kalo di YouTube tuh banyak yang printilannya yang sebetulnya sangat simpel, tapi krusial karena cukup detail kan untuk dikerjain. Nah emang enaknya gitu, mereka tinggal syuting, beres, mereka share dan sebarin ke followers atau temen-temen mereka. Bahkan materi promo juga udah kita siapin. Itu juga alasan kenapa seorang kreator baiknya berada di bawah naungan MCN ya. Memudahkan mereka (Ega, 2020).

\section{Tahap Konfirmasi (Confirmation)}

Tahap konfirmasi merupakan tahap terakhir. Pada tahap ini seseorang akan mencari pembenaran atas pilihan yang telah mereka buat. Tidak akan menutup kemungkinan bila nantinya keputusan yang sudah diambil akan berubah, seperti awalnya menolak, namun ternyata setelah melakukan evaluasi ia malah akhirnya menerima inovasi yang ditawarkan (Setijaningrum, 2016).

Ega mengatakan, sejauh ini kreator yang berada di bawah naungan Collab Asia memberikan feedback yang baik. Terdapat beberapa kasus terjadi, kreator memutuskan untuk tidak melanjutkan kerja sama dengan Collab Asia. Namun mereka akan menginvestigasi hal tersebut dan akan mencoba melakukan persuasi ulang atau evaluasi agar dapat meningkatkan mutu produk dan jasa mereka. 
Terdapat beberapa kreator pada tahapan keputusan menolak inovasi yang diberikan oleh Collab Asia. Jika mereka sudah menawarkan inovasi pada tahapan pengetahuan dan persuasi sesuai dengan aturan yang berlaku tapi penolakan tetap terjadi, mereka pun memaklumi dan tidak akan memaksakan. Namun pada beberapa kasus, terjadi juga perubahan keputusan walaupun dalam jangka waktu lama dari tahapan pengetahuan, tapi tim Collab Asia siap kembali ke tahapan awal untuk memberitahu dan menginformasikan kepada kreator mengenai detail produk dan jasa mereka dari awal.

Karena ada aja case-nya ketika kita udah approach mereka di hari ini, jawaban mereka selanjutnya tidak. Tapi ada aja suatu saat mereka akan kembali ke kita, mungkin ketemu isu lainnya dan malah kontak kita dengan menanyakan apakah kira-kira offer kita masih berlaku atau tidak. Itu terjadi dan kita tidak pernah tutup pintu kerja sama (walaupun sudah pernah ada rejection) seperti itu. Kita welcome banget (Ega, 2020).

Menurut Sandy, ia bahkan sudah melakukan konfirmasi dengan inovasi yang ditawarkan Collab Asia dengan produk dan jasanya yang sesuai dengan ekspektasi, bahkan lebih, dari yang awal ia kira. Sandy yakin bahwa akan terus berada di bawah naungan Collab Asia, bahkan ketika kontrak kerja sama sudah berakhir.

Walaupun baru merasakan sekitar enam bulan bersama Collab Asia, Sandy bakal terus sama Collab Asia kok karena mereka juga sudah handle Sandy dengan profesional dan menyenangkan. Walaupun sudah lebih habis kontrak dua tahun, akan terus lanjut. Sandy gak mau ninggalin, he he (Sandy, 2020).

Pada tahap konfirmasi, Collab Asia berusaha lebih meyakinkan para kreator untuk dapat mengetahui secara langsung mengenai Collab Asia dan inovasi produk serta jasa yang mereka tawarkan, seperti menghampiri kreator yang berada di luar Jakarta, khususnya Jabodetabek, agar mereka merasa aman dan tidak merasa sedang terjerat penipuan atau semacamnya. Collab Asia akan menjadwalkan perwakilan talent manager mereka untuk melakukan city tour dan mendatangi kreator yang tersebar di berbagai daerah di Indonesia, guna melakukan bonding dan melakukan proses konfirmasi dengan komunitas kreator tersebut. Berikut ini proses tahapan adopsi inovasi antara Collab Asia dengan Sandy SS.

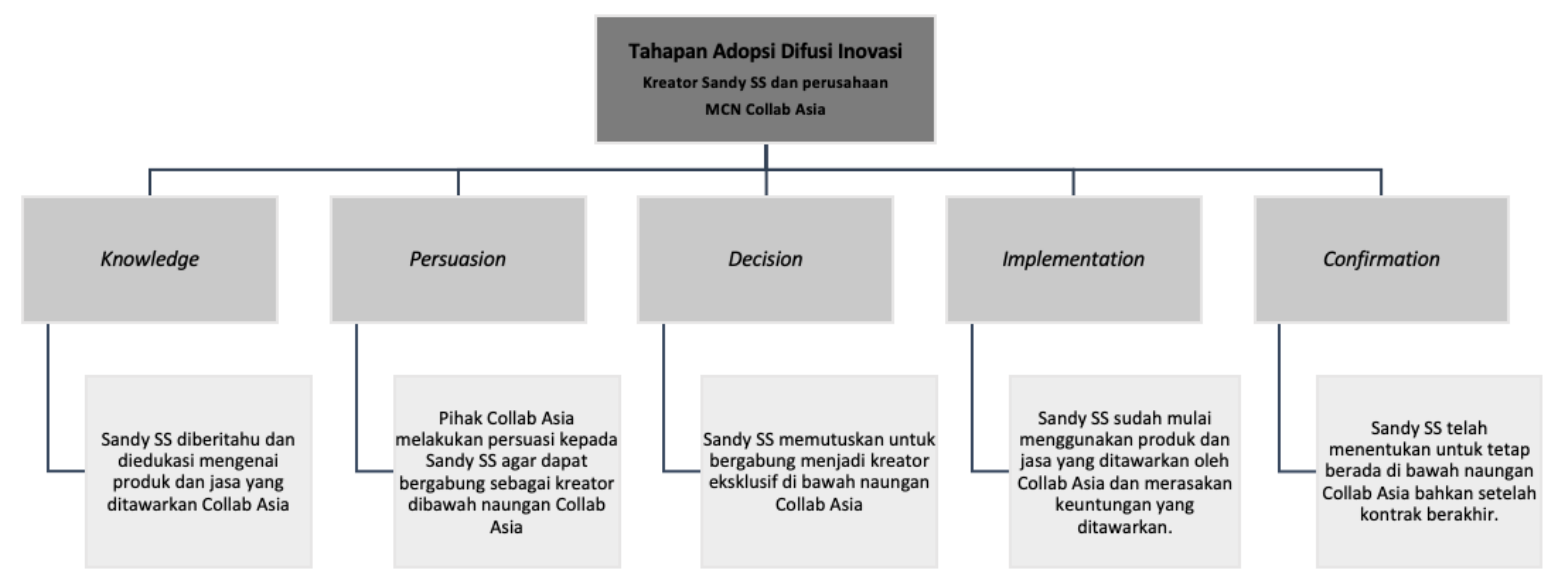

Gambar 3. Tahapan adopsi inovasi oleh kreator Sandy SS dan Collab Asia

(Peneliti, 2020) 


\section{PENUTUP}

Berdasarkan hasil penelitian Collab Asia dan kreator ditemukan kelima tahapan adopsi inovasi dimulai dari knowledge, persuasion, decision, implementation, hingga confirmation berjalan baik. Collab Asia memastikan kelima tahapan itu berjalan didasarkan dengan peraturan dan juga tata cara yang telah ditetapkan, baik peraturan perusahaan Collab Asia sendiri, maupun dengan adanya peraturan yang langsung diluncurkan oleh YouTube Headquarter, serta persetujuan yang sudah disepakati antara Collab Asia dan kreator. Namun, ada beberapa hal yang dapat ditingkatkan yaitu saluran komunikasi pada tahapan pengetahuan. Sebab saat observasi melalui pencarian di internet nama Collab Asia belum terekspos dengan baik. Dengan peningkatan saluran komunikasi dan strategi pemasaran atau kehumasan, maka pengetahuan masyarakat mengenai perusahaan MCN Collab Asia dapat lebih baik lagi.

\section{REFERENSI}

Azzura, S. N. (2015). KapanLagi Network Perkenalkan Multichannel Network. Dikutip dari https://www.merdeka.com/teknologi/kapanlagi-network-perkenalkan-multichannelnetwork.html. Diakses pada 3 Juni 2020.

Chau, C. (2010). YouTube as a participatory culture. New directions for youth development, 2010(128), 65-74

CNN Indonesia. (2018). Raditya Dika Beberkan Kesulitan Produksi Konten Media Sosial. Dilansir dari https://www.cnnindonesia.com/teknologi/20180902124309-185326904/raditya-dika-beberkan-kesulitan-produksi-konten-media-sosial. Diakses pada 3 Juni 2020.

Collab Asia. (2020). Our Story: About Collab Asia. Diambil dari https://collabasia.co/ourstoryl. Diakses pada 26 Maret 2020.

Collab. (2020). About Collab. Diambil dari https://www.collab.inc/about. Diakses pada 26 Maret 2020.

Fatonah, S., \& Afifi, S. (2014). Difusi Inovasi Teknologi Tepat Guna di Kalangan Wanita Pengusaha di Desa Kasongan Yogyakarta. Jurnal Ilmu Komunikasi, 6(1), 42-59.

Guntara, M. I. (2018). Tinjauan Hukum Perjanjian Kerja Sama Antara Konten Kreator YouTube dan Multi-Channel Network. UNILA: Lampung.

Haryadi, T. (2018). Adaptasi Teori Difusi-Inovasi Dalam Game "Yuk Benahi" Dengan Pendekatan Komunikasi SMCR. Jurnal Audience: Jurnal Ilmu Komunikasi, 1(1), 1-13.

Hootsuite. (2020). We Are Social, Indonesian Digital Report 2020. Diambil dari https://andi.link/hootsuite-we-are-social-indonesian-digital-report-2020/. Diakses pada 8 Januari 2021.

Howard \& Parks, M. R. (2012). American Behavioral Scientist, Vol. 45 No. 3, November $2001383-404$.

Jenkins, H. (2009). What happened before YouTube. YouTube: Online video and participatory culture, 109-125. 
Kaplan, A. M., \& Haenlein, M. (2010). Users of the world, unite! The challenges and opportunities of Social Media. Business horizons, 53(1), 59-68.

Kata Data. (2020). 10 Media Sosial Paling Sering Digunakan di Indonesia. Diambil dari https://databoks.katadata.co.id/datapublish/2020/02/26/10-media-sosial-yang-palingsering-digunakan-di-indonesia. Diakses pada 8 Januari 2021.

Kotler, P., \& Keller, K.L. (2009). Manajemen Pemasaran Jilid 1, edisi Ketiga Belas, Terjemahan Bob Sabran, MM. Penerbit Erlangga, Jakarta

Kurnia, T. (2018). Mau Jadi Bintang YouTube? Lebih Baik Kamu Pikir Ulang. Dilansir dari https://www.liputan6.com/tekno/read/3335944/mau-jadi-bintang-youtube-lebih-baikkamu-pikir-ulang. Diakses pada 3 Juni 2020.

Lumen Learning. (2017). The Spread of New Product. Diambil dari https://courses.lumenlearning.com/boundless-marketing/chapter/the-spread-of-newproducts/. Diakses pada 2 Juni 2020.

Mosqueda, M. W. (2019). Digital Media Firm Collab Asia Raises \$7.5m Series B from Korean Investors. Diambil dari https://www.dealstreetasia.com/stories/collab-asiaseries-b-165171/. Diakses pada 27 Maret 2020.

Neuman, W. L. (2014). Social Research Methods: Qualitative and Quantitative Appraoches. 7th ed. Essex: Pearson Education Limited.

Putri, I. D. A. H. (2013). Difusi Inovasi Dalam Komunikasi Pemasaran Politik Indonesia. Communication, 4(2).

Putri, Restu Diantina. (2018). Kevin Hendrawan, Sebagai YouTuber Kami Sering Tekor. Diambil dari https://tirto.id/kevin-hendrawan-sebagai-YouTuber-kami-sering-tekorcEUP. Diakses pada 27 Maret 2020.

Rahardjo, M. (2017). Studi kasus dalam penelitian kualitatif: konsep dan prosedurnya. Disampaikan pada mata kuliah Metode Penelitian, Sekolah Pascasarjana Universitas Islam Negeri Maulana Malik Ibrahim Malang, Januari 2017.

Rogers, E. M. (2010). Diffusion of innovations. Simon and Schuster.

Rusmiarti, D. A. (2016). Analisis Difusi Inovasi dan Pengembangan Budaya Kerja Pada Organisasi Birokrasi. Masyarakat Telematika Dan Informasi: Jurnal Penelitian Teknologi Informasi dan Komunikasi, 6(2), 85-100.

Setijaningrum, E. (2016). Kompetensi Soft Skill Aparat Pada Pelayanan Administrasi Terpadu Kecamatan (Paten) Dalam Perspektif New Public Service Di Surabaya (Doctoral dissertation, UNIVERSITAS AIRLANGGA).

Slameto, S. (2019). Reformasi Pendidikan Era Masyarakat 5.0. Jurnal Ilmiah Pendidikan TRISALA, 3(15), 412-419

Tolba, A. H., \& Mourad, M. (2011). Individual and cultural factors affecting diffusion of innovation. Journal of International Business and Cultural Studies, 5, 1.

Wimmer, R. D., \& Dominick, J. R. (2013). Mass media research. Cengage learning.

Yin, R. K. (1994). Case Study Research. Thousand Oaks, London, New Delhi: SAGE Publications. 
Youtube. (2020a). YouTube for Press. Diambil dari https://www.youtube.com/about/press/. Diakses pada 3 Juni 2020.

Youtube. (2020b). Manfaat dan Penghargaan. Diambil dari https://www.youtube.com/intl/id/creators/awards/. Diakses pada 3 Juni 2020.

Yuniar, N. (2015). Pertumbuhan Video YouTube Indonesia Terbesar se-Asia Pasifik. Dilansir dari https://www.antaranews.com/berita/524666/pertumbuhan-video-youtubeindonesia-terbesar-asia-pasifik\#mobile-nav. Diakses pada 3 Juni 2020. 